\title{
XXXV. Observations on the tests for arsenic
}

\section{Aug. Ludw Giseke}

To cite this article: Aug. Ludw Giseke (1825) XXXV. Observations on the tests for arsenic , Philosophical Magazine Series 1, 66:330, 252-259, DOI: 10.1080/14786442508673958

To link to this article: http://dx.doi.org/10.1080/14786442508673958

曲 Published online: 10 Aug 2009.

Submit your article to this journal 주다

LII Article views: 2

Q View related articles $\asymp$ 
remarkable; but I have no doubt that Mr. Burns will now regret that he has been so hasty in attributing the discordance to the principles of Dr. Brinkley's solution.

Greenwich Hospital, Oct. 6, 1825.

I am, sir, yours, \&c.

E. RIDDLE.

XXXV. Observations on the Tests for Arsenic*. By Auc. Ludw. Grseke.

\section{On the Detection of Arsenic by Lime-water.}

I GIVE, by way of introduction, a short account of some experiments on the subject, made some time since at this university, and which were occasioned by the following passage in Berzelius's excellent Instructions in Chemistry (Lehrbuche der Chemie). Berzelius mentions in the second volume of this work, p. 152 (according to Palmstedt's translation), the chemical detection of poisoning by arsenic, for which he gives the following process as proposed by Rose, with some additions of his own: "Cut up the coats of the stomach, and place them in the liquid, which is boiled with a few drachms of caustic potash, in order to dissolve any arsenious acid that might be contained in it. The solution obtained is filtered, heated till it boils, and during the boiling mixed with nitric acid, which is added in small portions as long as any thing separates, and till the liquid has become strongly acid, clear, and of a bright yellow colour. It is filtered while hot, afterwards nearly, not completely, saturated with carbonate of potash, and made to boil, in order to expel the carbonic acid; then it is boiled with clear lime-water as long as a precipitate is formed. The lime-water first saturates the excess of acid, and then precipitates with the arsenious acid as arsenite of lime, and with the phosphoric acid and other animal substances decomposed in the nitric acid. If instead of saturating the acid with limewater, you add first caustic alkali, till the liquid becomes alkaline, and then add lime-water, no precipitate will be formed, because the arsenite of lime is held in solution by the alkali."

It has been already observed by Hahnemann, that the arsenite of lime is dissolved even by the weakest acid of any kind; but no one noticed before Berzelius that it was also soluble in a saturated alkaline solution; and it also contradicted the experiments made by Prof. Schweigger in his chemical lectures,

* From Schweigger's Journal, Band xiii. p. 359.-This article is condensed from several lectures given by the author at the Physical Seminary at Halle.

which 
which showed that arsenite of lime could not be dissolved even by a great excess of alkali. In these experiments, to liquids poisoned with arsenic, caustic potash as well as soda and ammonia were purposely added; and immediately on adding lime-water, a very copious precipitate of arsenite of lime was produced.

Prof. S. considered this subject the more worthy of being investigated, as it surprised him that so distinguished a chemist as Berzelius, - who is so justly respected as the first ana. lyst of our age, - should be opposed to nature in so simple a process. Besides, the rule laid down by this careful naturalist had been already pretty generally admitted. Thus Geiger, in his new and valuable Handbuche der Pharmacie, p. 431, says " that the precipitate produced by lime-water in a pure aqueous solution of arsenious acid might be dissolved by free acids or alkalis." And Buchner, in his Toxikologie, p. 405: "Limewater will produce a white precipitate as well in arsenious as in arsenic acid. In order to produce this effect, neither any free acid nor free lime-water must be in it." In reality there may be a great excess of lime-water, without the result being disturbed by it; on the contrary, it is beneficial to apply limewater abundantly: on which account Fischer justly recommends rather to put the solution of arsenic into lime-water, than the reverse, because the lime-arsenic is dissolved even by an excess of arsenious acid. But since neither arsenite nor arseniate of lime are dissolved, with any predominance of potash, soda, or ammonia; how was it that Berzelius obtained no precipitate with alkali in excess? The following experiment made by Prof. Schweigger in his lectures on chemistry will explain it.

Prepare an arsenical liquid, pour it into three glasses, and add to one portion an excess of caustic potash; to the second, excess of caustic soda; and to the third, excess of caustic ammonia. On adding lime-water, a deposit of arsenite of lime will be equally formed in each of the glasses. Now add to each a few drops of acid, (for instance, nitric acid,) yet so that in all the alkali shall predominate. Whilst no solution of the precipitate will take place in the glasses that have the potash and soda in them, it will immediately begin in that with the ammonia: and all the arsenite of lime will be finally dissolved, although the ammonia be not saturated by the acid which has been added. Of course the solution will take place in the three glasses when any acid is in excess; yet on saturating the acid with alkali, the precipitate will be re-formed immediately in those glasses that contain the potash or soda, but 


\section{Prof. Giseke's Observations on the Tests for Arsenic.}

not in that which holds the ammonia, however one may neutralize the liquid. The experiment may also be made by putting sal ammoniac or nitrate of ammonia into a liquid containing arsenic, and adding lime-water, which then will not give a precipitate, however great the quantity of lime-water that may be added; or the reverse, by pouring the arsenical solution into lime-water, and even heating the solution in order to concentrate it more. Thus it will be seen that in the experiment mentioned by Berzelius, and as he has observed himself, no precipitate will be obtained by neutralizing the nitric solution with ammonia, of which he probably made use. But it is not the ammoniac as caustic alkali, but the nitrate of ammonia which is thereby formed, that prevents the deposit; and if instead of the ammonia we employ caustic potash or soda for neutralizing the nitric acid, the precipitate of arsenite of lime will instantly be formed with lime-water, even with a prevalence of the alkali.

The results of these experiments lead us also to make a few remarks on the method of discovering arsenic in a poisoned liquid, proposed by M. Pfaff in his Manual of Analytic Chemistry. He says (vol. ii. p. 392), "If the white arsenic cannot be separated from the contents of the stomach, the whole substance must be boiled in a proportionate quantity of water and nitric acid. The liquid, which in consequence turns yellow, is filtered through a woollen cloth, and the clarified acidulous liquid mixed with acidulated solution of sulphuretted hydrogen as long as it continues to produce a lemon-coloured turbidity. One may also use lime-rwater instead of the sulphuretted hydrogen, and submit the arsenite of lime to sublimation with 1-4th of charcoal powder." Nevertheless it is evident, from the experiments above recited, that lime-water will not produce a precipitate of arsenite of lime, owing to the ammoniacal salt prevailing in the arsenicàl liquid.

Roloff likewise proposes in these kinds of experiments to neutralize the nitric acid with solution of caustic potash or ammonia*. If he has made a frequent use of the latter, it may be easily conceived why, deviating from Rose's plan, he has preferred to recommend sulphuretted hydrogen instead of lime-water, since the latter will give no result.

As the effect of an ammoniacal salt here observed, which is so similar to that observed by Mr. Gærtnert in arsenite of copper (Scheele's green), probably depends on double affinity,

* Vide Journ.f. Chem. u. Phys. vol, vii. (old series) p. 415.

+ Ibid. p. 426. 
-in which, however, we must suppose a much stronger affinity between the arsenic and the ammonia than between the arsenic and the potash or soda,-I have been requested by Professor Schweigger to make a series of experiments on the decomposition of arsenite of lime by the salts of ammonia. The following are the results.

A. I precipitated some arsenious acid with lime-water, and added to this liquid, in which the arsenite of lime was suspended in white flakes, the following ammoniacal salts in solution; viz. the muriate, nitrate, acetate, and sulphate. Each of these produced a solution of the arsenite of lime and clarified the liquid. But when I added to this liquid containing the arsenite of lime in flakes, phosphate or carbonate of ammonia, an effect was produced on the lime, but a deposit always remained. 'This shows evidently the existence of a double affinity, since the phosphoric and carbonic acids became precipitated in combination with the lime, but with the other ammoniacal salts the solution remains clear, as may be seen from the following experiments.

$a$. The precipitate formed by carbonate of ammonia effervesced in acetic acid, and diluted with water gave with oxalic acid a white precipitate of oxalate of lime.

$b$. By adding sulphuretted hydrogen to the clear supernatant liquid a yellow tinge was produced; with nitrate of silver a yellow, and with lime-water a white precipitate.

$c$. The solution above the precipitate produced by phosphate of ammonia, gave with sulphuretted hydrogen a yellow tinge; with nitrate of silver a yellow, and with lime-water a white precipitate.

B. Arsenite of lime newly precipitated was filtered off, and washed with distilled water : this pappy substance was then put into solutions of acetate, muriate, nitrate, and sulphate of ammonia, and completely dissolved; but in phosphate or carbonate of ammonia a precipitate remained, as described above.

C. The arsenite of lime being well dried was not dissolved by nitrate, acetate, or muriate of ammonia, at common temperatures; but when boiled the solution became quite clear. But if boiled with natural phosphate of ammonia, a precipitate of phosphate of lime remained.

\section{On the Detection of Arsenic by means of Iodine-starch.}

Brugnatelli was the first who stated that iodine-starch might be applied as a re-agent for arsenious acid. His essay on the subject may be found in the Journ. f. Chem. u. Plyys. vol. xx. p. 56. According to him, iodine-starch is deprived of colour by arsenious acid and by solution of sublimate; but the 


\section{Prof. Giseke's Observations on the Tests for Arsenic.}

blue colour is restored by the addition of concentrated sulphuric acid when the experiment has been made with arsenious acid, but not when sublimate has been used. Thus iodinestarch will serve as a true criterion to distinguish between those two kinds of poison.

Being one day present with my friend Moritz Hecker, at a judicial investigation of an alleged poisoning by arsenic, and the absence of both arsenic and sublimate having been ascertained by the acknowledged re-agents, we also tried iodinestarch. The liquid under examination having completely deprived it of colour, we were led to make a series of experiments on the decolorization of iodine-starch and the restoration of its colour. They completely confirmed what had already been affirmed by Stromeyer in Gilbert's Annalen, vol. xlix. p. 150, and by Colin and Gaultier de Claubry (Journ. vol. xiii. old series, p. 453-4.57); and nothing can be added, according to our experiments, to the substances mentioned by these chemists as decolorizing the iodine-starch, except prussic acid and prussiate of mercury. That protonitrate of mercury as well as sublimate would deprive it of colour might have been expected. But it deserves to be noticed, that whilst arsenious acid quickly decolorizes the iodine-starch, pure arsenic acid does not, although arseniate of potash and arseniate of ammonia render it colourless; after which, an addition of sulphuric acid restores the colour. The fuming sulphuric acid of Nordhausen, concentrated or somewhat diluted, completely decolorizes iodine-starch; wherefore the blue colour, if destroyed by arsenious acid, cannot be restored by the addition of fuming sulphuric acid, but only by the rectified acid.

On developing the fuming substance of the Nordhausen sulphuric acid by warmth, and introducing it into iodine-starch, it decolorizes it immediately. Even by warming in a phial one part of black oxide of manganese and two of Nordhausen sulphuric acid, with the view of converting the sulphurous acid that might perhaps be contained in the oil of vitriol into sulphuric acid, and introducing from time to time the vapours into iodine-starch, the latter was deprived of colour even after the mixture had been boiling for a quarter of an hour. Still it would be a mistake to ascribe the quality of decolorizing the iodine-starch to the fuming substance, which, according to F. C. Vogel's and Dobereiner's and Bussy's experiments, is nothing but sulphuric acid free from water; misled by the peculiar, and as yet imperfectly explained, affinity of the fuming substance to another colouring matter-indigo. On the contrary, the iodine-starch was found in these experiments the most powerful re-agent on the sulphurous acid. For by a repeated 
repeated treatment of Nordhausen sulphuric acid with black oxide of manganese, I obtained at last the fuming substance in such a state that, being perfectly free from sulphurous acid, it no longer decolorized the iodine-starch. Another experiment gave a further proof that it is only the sulphurous acid contained in the Nordhausen sulphuric acid which discolours the iodine-starch. For by introducing only as many drops of this fuming sulphuric acid into the starch as will just decolorize it, a little shaking of the liquid in the glass will reproduce the lost colour sometimes in a surprisingly short time. The restoration also takes place by exposing the iodine-starch, decolorized as stated, for some time to the influence of the atmosphere. But the colour is reproduced still more quickly by adding a few drops of nitric acid, just as it is in iodine-starch decolorized by sulphurous acid.

If the colour is removed by sulphuretted hydrogen, it is only restored by nitric or sulphuric acid, if no more sulphuretted hydrogen has been employed than was just necessary to remove the colour. For if the sulphuretted hydrogen be in excess, the colour can only be restored by the liquid's being boiled, and thus the excess of sulphuretted hydrogen removed. I made the attempt to remove this excess by freezing, but did not succeed : whence it may perhaps be asked, whether the separation of the hydrosulphuret of arsenic by freezing depends only on the expulsion of the excess of sulphuretted hydrogen, or on the power of crystallization, favoured by the cold.

It is also deserving of notice, that a decoction of onions decolorizes iodine-starch, and that the colour is afterwards restored by sulphuric acid, just as in the case of arsenic.-Of this, however more hereafter.

In conclusion, I would make the following remark on iodine-starch in its relations to arsenic. Neither Brugnatelli nor any one else has noticed that it is only fresh iodine-starch which is applicable as a re-agent on arsenic. Yet in the lectures in our university it was found that, unless perfectly fresh, it was useless for such experiments :-even if it was but one day old it was of no use, as will be seen in the sequel.

Iodine-starch (made by dropping a solution of iodine in alcohol into a solution of boiled starch in cold water, which had become clear by standing) was distributed in equal quantities and strength of colouring into four glasses. The glass $a$ contained iodine-starch just prepared; $b$, such as was one day old; $c$, such as had been a fortnight in a closed glass; and $\dot{d}$, Vol. 66. No. 330. Oct. 1825. 
Prof. Giseke's Observations on the Tests for Arsenic.

such as had been for a fortnight in an open glass. The starch in glass $a$ was decolorized by four drops of a solution of arsenic, and that in glass $b$ by twelve drops; whilst twentyfour drops of the same solution did not perfectly decolorize the iodine-starch in glasses $c$ and $d$. After two hours the liquid in glass $c$ was completely colourless, but that in $d$ was still violet. The restoration of the colour was perfectly effected in glass $a$ by eight drops of sulphuric acid, and in $b$ less perfectly by twelve drops; the liquid in $c$ and $d$ received its blueish colour again after the addition of sixteen drops, but did not assume a full blue even with a greater addition of sulphuric acid. It would perhaps not be easy to determine what change may have taken place in the iodine-starch by a short exposure to the atmosphere, in which the colour suffers no alteration whatever.-Perhaps I shall find an opportunity to make further experiments on the subject.

\section{Affinity of the Decoction of Onions for some Re-agents.}

As it has been frequently said that the decoction of onions bears the same affinity for the re-agents as arsenious acid (See Berzelius Lehrbuche der Chemie, vol. ii. p. 154), the subject was considered in our lectures, in order to show the similarity of the precipitates as they appear at first, and also the difference which is perceptible on a closer inspection.

Repeating this examination, I made the following experiments. A small onion was cut and boiled for a quarter of an hour in distilled water, and the decoction being strained off, it was treated with the following re-agents :

1. The red solution of camelion mineral was changed yellow.

2. The blue solution of ammoniated copper turned to a greenish hue.

3. Iodine-starch was decolorized, and the blue colour restored by the addition of sulphuric acid.

4. Sulphuretted hydrogen produced no change in the decoction.

5. Lime-water coloured it yellow, and produced after a little standing a yellowish deposit, but which was not dissolved, like the arsenite of lime, in salts of ammonia, nor was it altered by weak acids.

6. Nitrate of silver produced a white precipitate, which increased and became yellow by the addition of ammonia. On more ammonia being added it disappeared, but was reproduced on being neutralized with nitric acid; and again disap- 
peared with an excess of this acid,-quite similar in this respect to the arsenite of silver. If, however, this experiment be repeated several times, the yellow deposit does not re-appear; and instead of it a brownish one is produced after the lapse of several hours, which might be compared to that arising from nitrate of silver and arsenic acid.

Thus the three first-named re-agents have the same relations with a decoction of onions as with a solution of arsenious acid; but sulphuretted hydrogen, lime-water, and nitrate of silver exhibit distinct differences.

XXXVI. On the Construction of Sundials; with a Table for that purpose. By Mr. M. Sмiтн.

To the Editor of the Philosophical Magazine and Journal. Sir,

THE following table for the construction of sundials is carefully computed in conformity with the principles demonstrated in my letter published in your last Number, page 168. All similar tables which I have hitherto seen are extremely erroneous, being calculated on the supposition that the shedow is cast from the centre of the sun; and therefore any dial constructed from such tables must invariably err one minute of time from the truth. The following table is computed on the principle that the shadow is cast from a point in the sun's disc one minute of a degree within that limb which is nearest to the meridian, and consequently fifteen minutes from the sun's centre. The shadow therefore coincides with the meridian at one minute of time from noon. This remark must be particularly attended to, as it follows that the hour-angle for noon is negative; consequently the upper line in the table, or that standing opposite to $0^{\mathrm{h}} 0^{\mathrm{m}}$ is to be set off from the meridian in the contrary direction from all the others, which will have the effect of contracting the double hour-line for twelve o'clock, so as to render it somewhat less in thickness than the gnomon or style of the dial.

$$
\text { I remain, sir, }
$$

Your obedient servant,

October 5, 1825.

M. Sмiтн. 